\title{
Liste der befragten Expertinnen und Experten
}

1. Ing. Edip Bayizitlioglu, Geschäftsführer/Managing Director, WEDCO Handelsgesellschaft m.b.H.

2. Mag. Regina Haberfellner, Soll\&Haberfellner Unternehmens- und Projektberatung

3. Mag. Dr. Helmut Naumann, Abteilungsleiter, Wirtschaftskammer Wien, Abteilung Wirtschaftspolitik

4. Dr. Michael Parzer, Institut für Soziologie, Universität Wien

5. Jana Radić, MA, Expert Assistant, Department for Promoting Human Rights, Equality of Genders, Relations with National Minorities and Religious Communities and Civil Society Development, Municipality of Zagreb, Republic of Croatia

6. Franck Runge, Servithink Consulting Services

7. Mag. Edwin Schäffer, Leiter des Diversityreferats der Wirtschaftskammer Wien

8. Mag. Davor Sertic, Managing Director, Unitcargo Speditionsges.m.b.H.

9. Gabriela Tomášiková, MBA, Prokuristin, Unitcargo Speditionsges.m.b.H.

10. Tuncel Tülay, Wirtschaftsagentur Wien, Projektleiterin von Mingo Migrant Enterprises

11. Ing. Mario Vechiatto-Kunz, Servithink Consulting Services 